\title{
The Effect of Traditional Korean Medicine Treatment on CREST Syndrome: A Case Report
}

Jin-yong Joung, Hyun-sik Seo, Chang-gue Son, Nam-hun Lee, Jung-hyo Cho

Dept. of Internal Medicine, Dae-Jeon Oriental Hospital of Dae-Jeon University

\section{The Effect of Treatment with Traditional Korean Medicine on CREST Syndrome: a Case Report}

\author{
Jin-yong Joung, Hyun-sik Seo, Chang-gue Son, Nam-hun Lee, Jung-hyo Cho
}

Dept. of Internal Medicine, Dae-Jeon Oriental Hospital of Dae-Jeon University

\begin{abstract}
CREST syndrome is a form of limited cutaneous scleroderma that occurs only in certain parts of the body, such as the skin of the hands and face. CREST refers to the five main features of the syndrome: calcinosis, Raynaud's phenomenon, esophageal dysmotility, sclerodactyly, and telangiectasia. Currently, there is no standard treatment for CREST syndrome, and there have been no studies of the use of traditional Korean medicine (TKM) for this disease. This study describes the effects of Keumsuyukun-jeon on CREST syndrome. The patient in this case had typical clinical symptoms of CREST syndrome. These symptoms improved within a relatively short period of receiving the TKM treatment. The results of Anti-centromere antibody (AI) and high sensitivity C-reactive protein $(\mathrm{mg} / \mathrm{L})$ also improved.
\end{abstract}

Key words: CREST syndrome, traditional Korean medicine, case report

\section{Introduction}

Systemic sclerosis, often referred to as scleroderma, is a multi-organ disease characterized by structural abnormalities of blood vessels and fibrosis of organs such as skin, lung, heart, kidney, and digestive system caused by autoimmunity. This

· 투고일: 2017.03.10, 심사일: 2017.05.21, 게재확정일: 2017.05.25

- Corresponding author: Jung-hyo Cho Dept. of Internal Medicine, Dae-Jeon Oriental Hospital of Dae-Jeon University 34929, 176-9 Daeheung-ro, Jung-gu, Daejeon, South Korea

TEL: +82-42-229-68066 FAX: +82-42-254-3403 E-mail: choajoa@dju.kr disease is classified as either diffuse cutaneous scleroderma or limited cutaneous scleroderma and are mainly seen in middle-aged women with a genetic background. The exact cause of the disease is not known, but it is understood that endothelial cell damage and fibroblast activity due to autoimmunity cause fibrosis of the tissue 1 .

CREST syndrome is a form of limited cutaneous scleroderma that occurs only in certain parts of the body, such as the skin of the hands and face. CREST stands for the five main features of the syndrome, which are calcinosis, Raynaud's phenomenon, esophageal dysmotility, sclerodactyly, and telangiectasia ${ }^{2}$. 
CREST syndrome is known to account for 22-25\% of all scleroderma ${ }^{3}$, and is a rare disease that occurs in approximately 2.7-19.3 per 1 million adults in the United States. There have been few domestic and overseas studies, and none have been reported which traditional Korean medicine (TKM) treatments were applied. We report a case of typical CREST syndrome with improved clinical symptoms and blood test results after being treated with TKM treatment.

\section{Case}

\section{Patient symptoms and diagnosis}

In January, 2017, a 49 year old female named Lee, $\bigcirc$ visited the Korean internal medicine department of Daejeon University Korean Medicine Hospital for severe coughing with dyspnea, postprandial dyspepsia and received inpatient treatment for 22 days. The patient had been receiving treatment since being diagnosed with CREST syndrome at a tertiary General Hospital in 2012. Since a month before her first visit, her symptoms worsened to such an extent that she was unable to carry out everyday life after being overstressed at work. She had no history of trauma, surgery, alcohol, or smoking, and was taking vascular strengtheners, circulation improvers and ulcer remedies after the diagnosis in 2012.

She was $166 \mathrm{~cm}$ tall and weighed $57.7 \mathrm{~kg}$ at the time of admission, and her blood pressure was 150/90 $\mathrm{mmHg}$, pulse 78 times/min, respiratory rate 20 times/min, and body temperature $37.0{ }^{\circ} \mathrm{C}$. In the physical examination, both hands showed scleroderma with skin thickened by progressed fibrosis, and calcification symptoms such as keratinization of the periphery of the lips were observed (Fig. 1, 2). Raynoud's phenomenon was observed at the extremities of the limbs as the environment changed. Esophageal dysmotility caused digestive symptoms such as postprandial discomfort and hunger sore and violent spasmodic coughing, and reddened vascular enlargement of the face and limbs was observed. Among her symptoms, the patient complained most about the coughing and digestive symptoms.

At the time of admission, the blood test results were mostly normal, but there were abnormality in the indexes related to autoimmune inflammation (Table 1). Urine analysis, chest X-ray and electrocardiography were also normal.

Table 1. Indexes Related to Autoimmune Inflammation

\begin{tabular}{ccc} 
Indexes related to autoimmnity & $\begin{array}{c}\text { Normal } \\
\text { range }\end{array}$ & Level \\
\hline $\begin{array}{c}\text { Anti-nuclear antibody } \\
\text { (Qualitative examination) }\end{array}$ & - & Positive \\
Anti-centromere antibody (AI) & $0-1$ & 1670 \\
$\begin{array}{c}\text { Erythrocyte sedimentation rate } \\
\text { (ESR) (mm/hr) }\end{array}$ & $0-20$ & 16 \\
$\begin{array}{c}\text { High sensitivity C-reactive protein } \\
\text { (hs-CRP) (mg/L) }\end{array}$ & $0-1$ & 1.69 \\
$\begin{array}{c}\text { Rheumatoid factor } \\
\text { (RF) (IU/mL) }\end{array}$ & $0-14$ & 11.3 \\
\hline
\end{tabular}

The patient had five typical clinical manifestations of the CREST syndrome: Calcinosis, Raynaud's phenomenon, esophageal dysmotility, sclerodactyly, and telangiectasia. Her blood test revealed specific findings such as positive ANA and ACA, elevated $\mathrm{CRP}$, and therefore, she was diagnosed with typical CREST syndrome. 


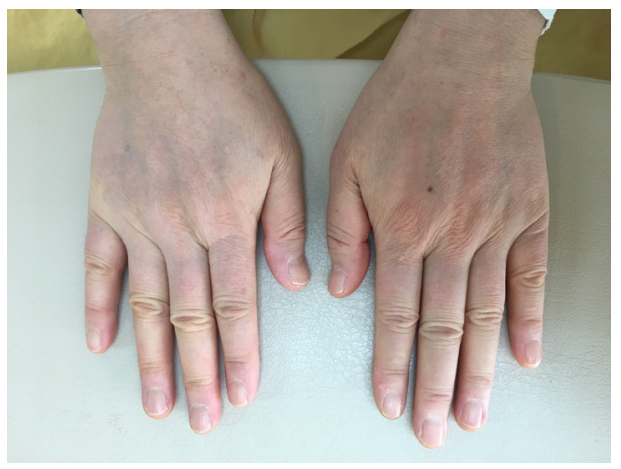

Fig. 1. Patient's hands.

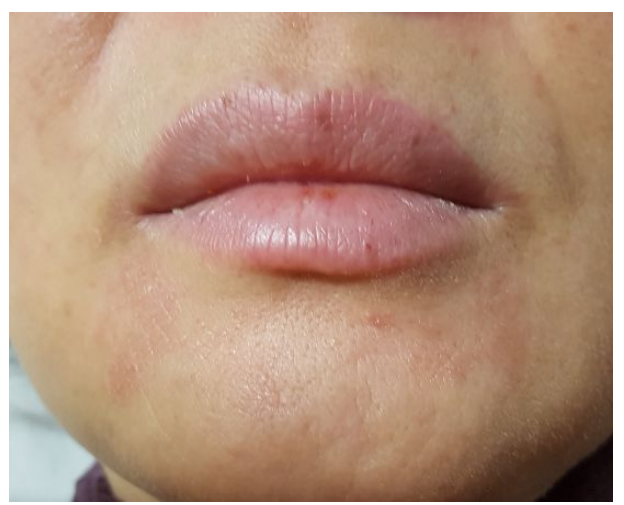

Fig. 2. Patient's mouth periphery.

\section{Treatment and progress}

From the first day of admission to the 22nd day of hospitalization, acupuncture treatment was performed twice a day, based on the oriental medicine theory. We used stainless steel needles having a thickness of $0.20 \mathrm{~mm}$ and a length of 15mm. The acupoints used were: L-9 (太淵), LI-7 (溫溜), PC-4 (郄門), GB-40 (圻墟), PC-8 (勞宮), GB-34 (陽陵泉), KI-10 (陰谷), SP-8 (地機), LU-5 (尺澤). 80 cc of Keumsuyukun-jeon (Table 2) was given to drink three times a day after meals. Moxa and hot packs were applied. Her usual treatment of Nicergoline $10 \mathrm{mg}$ qd, Vitis vinifera ext. $150 \mathrm{mg}$ and Rebamipide $100 \mathrm{mg}$ bid were continually given to her.
The treatment was assessed by comparing the degree of spasmodic coughing and digestive symptoms, which were the most severe symptoms, during hospitalization. Visual analogue scale (VAS) was used as a method to objectify and quantify subjective symptom severity ${ }^{5}$. Cough symptoms gradually improved from VAS 9.2 at admission to VAS 5.0 on day 21. Digestive symptoms also improved from VAS 9.3 at admission to VAS 5.5 on day 21 (Fig. 3). Biochemical tests showed hs-CRP of 1.69 $\mathrm{mg} / \mathrm{L}$ on the second day of hospitalization and $0.79 \mathrm{mg} / \mathrm{L}$ on day 20. The ACA was 1670AI on the second day of admission and decreased to 1360AI on day 20 of admission (Table 3).

The patient's subjective discomfort due to Raynaud's phenomenon was reduced to about $60 \%$ on the 22nd day of admission, and the overall condition felt by the patient also improved. However, there was no significant change in the appearance of scleroderma on both hands and the periphery of the lips between the time of admission and the 22nd day. The red dots on parts of the face and limbs remained. The patient was discharged on the 22nd day of hospitalization and is currently undergoing outpatient treatment and showing improved condition.

Table 2. Prescription of Keumsuyukun-jeon

\begin{tabular}{cc} 
Herbal name & $\begin{array}{c}\text { Amount } \\
\text { per day }(\mathrm{g})\end{array}$ \\
\hline Rehmanniae Radix Preparata (熟地黃) & 20 \\
Angelicae gigantis Radix. (當歸) & 8 \\
Dinelliae Tuber. (牛夏) & 8 \\
Poria cocas Wolf. (白获苓) & 8 \\
Aurantii nobilis Pericarpium (陳皮) & 12 \\
Glycyrrhizae Radix. (甘草) & 8 \\
Brassicae Semen (白芥子) & 6 \\
\hline Total & 70 \\
\hline
\end{tabular}


Table 3. Changes in Blood Test Results Associated with CREST Syndrome

\begin{tabular}{cccc} 
& $\begin{array}{c}\text { Normal } \\
\text { range }\end{array}$ & Day 2 & Day 20 \\
\hline $\begin{array}{c}\text { Anti-nuclear antibody } \\
\text { (Qualitative examination) }\end{array}$ & - & Positive Positive \\
$\begin{array}{c}\text { Anti-centromere antibody } \\
\text { (AI) }\end{array}$ & $0-1$ & 1670 & 1360 \\
$\begin{array}{c}\text { High sensitivity C-reactive } \\
\text { protein (mg/L) }\end{array}$ & $0-1$ & 1.69 & 0.79 \\
\hline
\end{tabular}

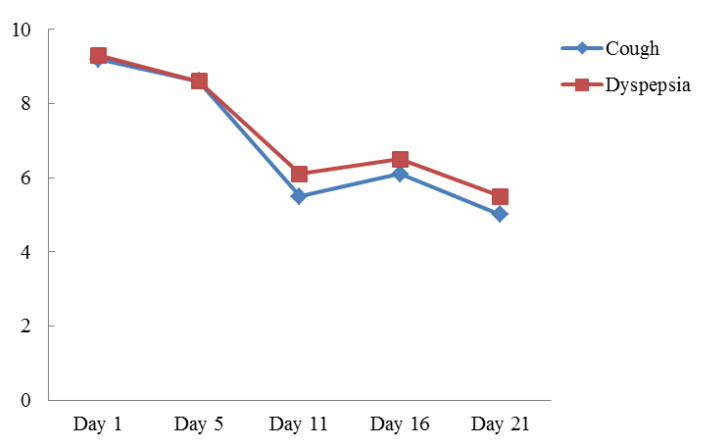

Fig. 3. VAS change of cough and dyspepsia.

\section{Discussion}

Scleroderma is a systemic autoimmune disease that causes fibrosis of the skin, lungs, heart, kidneys, digestive system, skeletal muscle, and causes structural abnormalities of blood vessels. CREST syndrome, which is a type of limited cutaneous scleroderma, has five typical symptoms: Calcinosis, Raynaud's phenomenon, esophageal dysmotility, sclerodactyly, and telangiectasia. To date, there is no cure for CREST syndrome, but immunosuppressants, antiplatelet agents, anti-fibrosis agents, and steroids are being used to relieve symptoms ${ }^{6}$.

Although the cause is unknown, the disease seems tobe associated with anti-nuclear antibodies (ANA) and anti-centromere antibodies (ACA), with ANA being positive in $85 \%$ of patients with systemic sclerosis? ${ }^{7}$ and ACA, which is a more specific marker, seen in $82-96 \%$ of the patients with CREST syndrome ${ }^{8}$. Nonspecific indicators of inflammation, such as erythrocyte sedimentation rate (ESR) and C-reactive protein (CRP), are also relatively rare, but may increase in CREST syndrome. Serial testing of autoantibodies to identify disease progression is generally not recommended, but there is clinical evidence that the titer of ACA is related to severity of vascular disease and Raynaud's phenomenon ${ }^{10}$.

There has been little study done on CREST syndrome, which accounts of only 22 to $25 \%$ of systemic scleroderma, already a rare disease. Although there currently is no standard treatment for CREST syndrome, there is no study done on the use of TKM in this disease. Jang has reported using an electrogastrogram device for the improvement of digestive disorders ${ }^{11}$ and Kim reported that the patient's skin and musculoskeletal symptoms improved with the pain assessment tool table in cases of systemic sclerosis ${ }^{12}$, which is a larger category than CREST syndrome.

In this case, the patient was diagnosed with CREST syndrome at a tertiary General Hospital in 2012 and received continuous treatment. However, a month before admission, symptoms of cough and dyspepsia worsened to a point where every day life was impossible, and he visited our hospital seeking TKM treatment. At the time of admission, the patient showed subcutaneous calcification symptoms such as percutaneous skin changes and keratinization of the peripheries of the lips. When exposed to the cold or when under stress, numbness and itchiness of the extremity of the limbs, known as Raynoud's phenomenon appeared. Additionally, esophageal dysmotility caused nausea, digestive 
symptoms such as dyspepsia, and severe spasmodic cough. Telangiectasia with redness was observed on areas of the face. Immunohistochemistry showed that ANA and ACA were positive and elevated hs-CRP was also observed, diagnosing the patient with typical CREST syndrome.

To restore esophageal function, acupuncture was performed twice a day according to TKM theory. Keumsuyukun-jeon is administered to weak patients who are breathless after coughing and suffer from nausea, and has been reported in animal studies to restore respiratory mucosal abnormalities and to inhibit allergic reactions and infiltration of inflammatory cells ${ }^{13-15}$. In Korean traditional medicine, the crest syndrome patient was diagnosed to have insufficient moisture in the body. So we selected the acupuncture points that add moisture to the skin and muscles. Keumsuyukun-jeon was also used for adding moisture to the body.

This patient had progressive improvement of spasmodic cough symptoms and indigestion symptoms during admission. Each VAS also gradually improved, but when the patient was exposed to stress due to personal problems on the 15th day after admission, all the symptoms became worse and the VAS score increased. Scleroderma, like other autoimmune diseases, is known to develop or worsen under stress or environmental changes ${ }^{16}$, and the patient also experienced disease aggravation after severe stress in the workplace a month before admission.

Blood tests showed that the activity of ACA, the most specific marker of CREST, was also reduced by about $20 \%$, and the elevated hs-CRP decreased to normal range on the 20th day after admission. A clinical observation by Buchanan RR et al reported that ACA activity is correlated with Raynaud's syndrome and vascular disease ${ }^{10}$, and suggests that the ACA titer reduction in this patient is meaningful for the patient's prognosis improvement. CRP, which is also a nonspecific indicator of inflammation, is a marker for the progression of various autoimmune diseases, and reductions in CRP indicate reduced autoimmune activity $^{17}$.

In relation to the safety of this treatment, no adverse effects such as skin damage or inflammation were observed during acupuncture treatment, and no side effects due to herbal medicine were observed. Blood tests performed on the 20th day of admission showed no significant change in liver function tests, renal function tests, and urinalysis compared to those done on admission.

The limitation of this study is that it is difficult to identify the effect of TKM alone on CREST syndrome as the patient received both TKM and western medicine treatment simultaneously. However, the patient's western medication was taken continuously for 5 years ever since the diagnosis was first made in 2012, and the effect is thought to be weak considering the fact that the symptoms have worsened through out the treatment. TKM treatment with acupuncture and herbal medicines improved both the subjective symptoms of the patient and related indicators on the blood test within a relatively short period of 3 weeks and was safe without side effects. The authors wish to expand the baseline of TKM for rare diseases through this case and report that oriental treatment for CREST syndrome was effective.

\section{Acknowledgments}

This study was supported by the Association of Sang-Su Medicine (ASSM) which is one of the 
Traditional Oriental Medicine study group in South of Korea.

\section{Reference}

1. Allanore Y, Simms R, Distler O, Trojanowska M, Pope J, Denton CP, et al. Systemic sclerosis. Nat Rev Dis Primer 2015:23(1):15002.

2. Winterbauer RH. Multiple telangiectasia, Raynaud's phenomenon, Sclerodactyly, and Subcutanious Cacinosis: A Syndrome Mimicking Hereditary Hemorrhagic Telangiectasia. Bull Johns Hopkins Hosp 1964;114:361-83.

3. Steen VD, Powell DL, Medsger TA Jr. Clinical correlations and prognosis based on serum autoantibodies in patients with systemic sclerosis. Arthritis Rheum 1988:31(2):196-203.

4. Mayes MD, Lacey JV Jr, Beebe-Dimmer J, Gillespie BW, Cooper B, Laing TJ, et al. Prevalence, incidence, survival, and disease characteristics of systemic sclerosis in a large US population. Arthritis Rheum 2003:48(8):2246-55.

5. Huskisson EC. Measurement of pain. Lancet Lond Engl 1974;2(7889):1127-31.

6. Velayos EE, Masi AT, Stevens MB, Shulman LE. The 'CREST' syndrome. Comparison with systemic sclerosis (scleroderma). Arch Intern Med 1979:139(11) :1240-4.

7. van Paassen P, Damoiseaux J, Tervaert JW. Laboratory assessment in musculoskeletal disorders. Best Pract. Res. Clin Rheumatol 2003;17(3) :475-94.

8. Aeschlimann A, Meyer O, Bourgeois P, Haim T, Belmatoug N, Palazzo E, et al. Anti-Scl-70 antibodies detected by immunoblotting in progressive systemic sclerosis: specificity and clinical correlations. Ann. Rheum Dis 1989;48(12):992-7.

9. Muangchan C, Harding S, Khimdas S, Bonner
A, Baron M, Pope J. Association of C-reactive protein with high disease activity in systemic sclerosis: results from the Canadian Scleroderma Research Group. Arthritis Care Res 2012:64(9):1405-14.

10. Buchanan RR, Riglar AG. The titre of anticentromere antibodies: its relationship to Raynaud's phenomenon and vascular occlusion. Br J Rheumatol 1989;28(3):221-6.

11. Shim YS, Kim GB, Han JH, Kim SH, Kim EG, Kim SU, et al. A Case Report of Korean Traditional Medical Therapy on Gastric Dysmotility Involved in Patient with Systemic Sclerosis Sine Scleroderma. J Int Korean Med 2004;25(2) :344-51.

12. Kim MK, Jeong JG, Kim KM, Kim HJ, Kim $\mathrm{JH}$, Kim YI, et al. The Effect of Korean Medical Treatment on Systemic Sclerosis : A Case Report. The Acupuncture 2016:33(3) :207-18.

13. Kim CS, Choi HY, Kim JD. Effects of Kumsooyukkunjeon on Asthma Induced by Ovalbumin in Mice. J Korean Orient Med 2002;23(3):104-18. 14. Jo JK, An CG, Kim KJ, Kim NK, Park MC. Effects of Kumsooyukkun-jeon extract on the Ovalbumin-Induced Allergic Asthma in Mice. $J$ Korean Med Ophthalmol Otolaryngol Dermatol 2007:20(3) :107-17.

15. Song JJ, Park YC, Kim BT, Kim SH, Keum BT, Keum SH. Effect of Kamkeumsooyukkunjeon on Allergy and Lung Damage. Korean $J$ Orient Physiol \& Pathol 2000;14(2):70-9.

16. Hui KK, Johnston MF, Brodsky M, Tafur J, Kim Ho M. Scleroderma, Stress and CAM Utilization. Evid-Based Complement Altern Med 2009:6(4) :503-6.

17. Szalai AJ. C-reactive protein (CRP) and autoimmune disease: facts and conjectures. Clin Dev Immunol 2004;11(3-4) :221-6. 